\title{
A HISTÓRIA E O SEU ENSINO NA FACULDADE ${ }^{1}$
}

Eurípedes Simões de Paula

O professor de História da Civilização Antiga e Medieval, que vos fala neste momento, aqui se encontra apenas em virtude de uma praxe que já se tornou tradição nesta faculdade: é ao professor catedrático mais novo, que ainda não proferiu sua aula inaugural, que cabe ministrá-la.

Ao receber a ordem-convite do exmo. sr. diretor imediatamente entrevimos uma dificuldade: organizar uma aula que pudesse interessar a um auditório tão heterogêneo como este, composto de professores e alunos das mais diversas disciplinas desta faculdade, desde a Filosofia até a Química. Entretanto, em todos os cursos desta casa existe um denominador comum: a história do desenvolvimento das ideias e práticas que atualmente são aqui ministradas. Foi, pois, pensando nisso, que tivemos a ideia de, rapidamente, sem pretensões, discorrer sobre um tema que, se não agradar inteiramente, pelo menos poderá ser objeto de crítica e de debate geral: a História e o seu ensino nesta faculdade.

À guisa de modelo inspiramo-nos na magnífica aula inaugural que o mestre Lucien Febvre pronunciou em 1941, durante a feroz ocupação do solo de França pelo invasor nazista, aos alunos da École Normale Superieur de Paris. Muitas de suas ideias aqui estarão consubstanciadas.

Começa Lucien Febvre afirmando que a História é una. Realmente, só para efeitos didáticos é que costumamos dividi-la; daí, expressões como estas: história econômica, história social, história das ciências etc. Que será, pois, a História?

\footnotetext{
${ }^{1}$ Aula inaugural proferida no salão nobre da Faculdade de Filosofia, Ciências e Letras da Universidade de São Paulo, em 11 de março de 1949. Texto publicado originalmente em Filosofia, Ciências e Letras, n. 12, p. 73-82, 1949.
} 
Como a compreendermos? Para nós, História é o estudo cientificamente organizado das diversas atividades e das diversas criações dos homens d'outrora, examinadas no tempo e no espaço. A definição é um pouco longa, entretanto, é útil porque afasta, pelos seus próprios termos, falsos problemas.

Primeiramente, falamos de estudo cientificamente organizado e não de ciência, porque falar de ciência seria evocar a ideia de uma soma de resultados adquiridos e não acentuar o que há de mais interessante no historiador - a inquietação - motor que o faz dedicar-se apaixonadamente a um problema e tentar examiná-lo de um ângulo sempre diferente.

Em segundo lugar, falamos de homem, o único objeto da História. Assim, colocamos a História no grupo das disciplinas humanas - ao lado da Antropologia, da Psicologia, da Linguística etc. Mas a História não se interessa pelo Homem abstrato, eterno, imutável no seu fundo e perpetuamente idêntico a si próprio, mas, sim, pelo Homem membro de uma sociedade de uma época bem determinada, Homem dotado de funções múltiplas, de atividades diversas, de preocupações e aptidões variadas, todas se misturando, se chocando, se contrariando, e acabando por concluir entre elas uma paz de compromisso, um modus vivendi que se chama Vida.

Esse Homem, que é tirado pelo historiador do passado, é um todo, não pode ser dividido. O historiador estuda a vida passada e é, como dizia o grande mestre belga Henri Pirenne, "um homem que ama a vida e que sabe examinar”. O historiador pode interessar-se mais particularmente por uma das atividades desse homem do passado: as atividades econômicas, por exemplo. Mas com uma condição: a de não esquecer nunca que se trata inteiramente de um homem dentro da sociedade que ele forjou e que foi por ela moldado. É por isso que o epíteto social sempre se encontra junto ao de econômico, indicando que não é um fragmento do real, um dos aspectos da atividade humana - mas o próprio Homem, tirado da sociedade de que ele é membro.

Dito isto, passemos a uma outra questão: como deve se comportar o historiador perante a História? Antes de mais nada deve ele formular um problema, pois se não houver um problema não haverá História, mas sim narrações e meras compilações. Após o problema formulado deve ele elaborar hipóteses. Foi por isso que, em nossa definição de História, não falamos em ciência, mas, sim, em estudo cientificamente organizado. Outrora os historiadores viviam num respeito pueril e devoto ao fato histórico. Quanto mais fatos soubessem, mais adiantados estariam nos seus estudos. 
Os colegas de laboratório sabem melhor que nós que não basta olhar pela ocular do microscópio e ver uma preparação de histologia, é necessário interpretá-la. Com os historiadores acontece o mesmo. Eles devem examinar os fatos, recorrer aos testemunhos os mais variados possíveis e às vezes contraditórios. Depois do exame crítico terminado, então podem reconstruir o mais perfeitamente possível o acontecimento em causa. Quando o historiador não formular problemas e elaborar hipóteses, podemos ter a certeza de que ele está atrasado em relação aos modernos estudiosos de nossa disciplina. Quando compulsamos grossos in-fólios, cuja redação levou anos de trabalho árduos a muitos historiadores, ou então manuais cuidadosamente preparados, bem redigidos, cheios de fatos, algarismos, datas, enumerações, ilustrações, ou ainda livros premiados por institutos de cultura, e neles encontramos pelo menos uma ideia nova e a marca de sua continuidade através dos tempos, damo-nos por satisfeitos. Mas, muitos espíritos ridicularizam a História pelo gasto de papel, de tempo, de dinheiro, apenas por uma ideia central. Daí, certas campanhas virulentas que a História tem sofrido, daí, a desafeição de jovens estudantes, daí, a crise por que passou a História. Há cinquenta anos, em França, a História saiu vencedora de violento combate, pois conseguiu conquistar todas as disciplinas humanas: a crítica literária transformou-se em história literária depois de Gustave Lanson: a crítica estética mudou-se em história da arte com André Michel e até as velhas controvérsias religiosas transmutaram-se em história das religiões.

Entretanto, novas disciplinas se formaram. A Psicologia renovou seus métodos e seu objeto sob o impulso de Ribot, Janet e Dumas; a Sociologia se constitui em ciência a parte com Durkheim, Simiand e Mauss. A Geografia Humana desenvolveu-se com Vidal de la Blanche, Demangeon e Jean Brunhes. Para a História ficava apenas a parte enfadonha da história diplomática, da história política, da história "batalha". Por isso, muitos espíritos acharam que dedicarse à História seria pura perda de tempo. Contra essa História "historizante" levantaram-se Lucien Febvre e Marc Bloch, seguidos de esplêndida plêiade de discípulos, colaboradores e colegas de ensino superior, como: Joseph Cuvelier, Albert Demangeon, Georges Espinas, Maurice Halbwachs, Henri Hauser, André Piganiol, Charles Rist, Paul Rivet, André Siegfried, Gaetan Pirou. Foram eles mais tarde completados por Fernand Braudel, Henri Brunschwig, Georges Friedman, Jean Gagé, C. E. Labrousse, Georges Lefebvre, Charles Morazé e outros. São eles que se insurgem em França contra esse velho modo de ver a História e, em consequência, enveredam pela história econômica e social. Esse 
movimento francês é idêntico e paralelo a outros em diversos países da Europa Ocidental.

A crise da História não foi apenas um fenômeno exclusivamente histórico. Ela foi antes um dos aspectos da grande crise de espírito humano, ou melhor, ela foi um dos sinais, ao mesmo tempo que uma das consequências de uma transformação muito nítida e toda recente, da atitude dos cientistas e dos sábios em face da Ciência. Temos de um lado o progresso espantoso da Física e do outro, a não menos interessante revolução no domínio da Biologia, com a Microbiologia e suas consequências. Assim, o Homem bruscamente mudou de mundo. Via, agora, diante de si, organismos semelhantes ao seu, visíveis a olho nu, em oposição a organismos só vislumbrados através da ocular do microscópio. Do outro lado, a teoria dos quanta, a teoria da relatividade transformando toda a ciência clássica, elaborada por gerações dos sábios, durante séculos de árdua e agitada vida. Todas as antigas teorias deveriam ser substituídas, todos os conhecimentos revistos.

Essa revisão foi total. Dela saiu o clima da Ciência dos nossos dias que estamos acostumados a sentir na nossa faculdade. Novos postulados foram formulados; eram eles completamente diferentes daquilo que se tinha como certo dez lustros antes. Deveria ficar somente a História fiel aos conhecimentos de outrora? Evidentemente, não. Deveriamos tomar por empréstimo aos homens de laboratório o espírito que dominava suas pesquisas há dezenas de anos? Evidentemente, sim. Como? Examinando os fatos históricos, confrontando os documentos e procurando explicar os acontecimentos e não nos atermos irracionalmente ao que está grafado, pois não poderemos, talvez nunca, saber com que intuito foram escritos certos textos que chegaram até nossos dias. Evidentemente, não podemos nos apoiar em conhecimentos que reconhecemos como tendo sido ultrapassados. Resolver inteiramente esse problema seria resolver a crise da História, essa verdadeira Tragédia do Progresso.

A História, atualmente, não é uma disciplina isolada, ela está intimamente ligada a outras ciências - como a Geografia, a Sociologia, a Economia política, a Filosofia etc. Essa necessidade de colaboração nós a podemos ver aqui mesmo na nossa faculdade, onde muitos assistentes de outras cadeiras ao elaborarem suas teses de doutoramento, inconscientemente ou não, apoiaram-se decididamente na História. Isso vem provar que estamos certos e que a orientação por nós seguida é moderna. Esse é precisamente o espírito dominante no grupo 
aglutinado por Lucien Febvre e Marc Bloch onde, ao lado de historiadores, aparecem geógrafos, sociólogos, etnógrafos, economistas etc.

História, Ciência do Homem. Postulado que não devemos esquecer jamais. Ciência da mudança perpétua das sociedades humanas, do seu perpétuo e necessário reajustamento a condições novas de existência material, política, moral, religiosa e intelectual. Ciência desse acordo que se negocia, dessa harmonia que restabelece perpétua e espontaneamente em todas as épocas, entre as condições materiais, condições técnicas, condições espirituais. É por aí que a História torna a encontrar a Vida. É por aí que ela cessa de ser acusada de mestra da vida, de impor aos vivos a lei dos mortos.

Todas essas ideias nós a ouvimos dos nossos mestres franceses que, desde 1934, estão colaborando com as nossas autoridades universitárias na ereção de uma verdadeira Faculdade de Filosofia, Ciências e Letras.

Assim, em 1934, tivemos a honra insigne de sermos discípulos do professor do Collège de France, Émile Coornaer, grande especialista em história econômica da Idade Média, principalmente do interessante problema das corporações de ofícios.

De 1935 a 1937 e, ainda, em 1940, tivemos entre nós o professor Fernand Paul Braudel, da École dês Hautes Études da Sorbonne, grande conhecedor da história moderna, principalmente do século XVI na Península Ibérica, e que há pouco mais de dois anos defendeu brilhante tese de doutoramento, depois de permanecer cinco anos num campo de prisioneiros de guerra e ter aí, como Henri Pirenne na $1^{\circ}$ Guerra Mundial, organizado uma verdadeira universidade - muito semelhante às universidades medievais pela impossibilidade da experimentação - de que foi reitor.

De 1938 a 1945, esteve entre nós o professor Jean Gagé, da Faculdade de Letras da Universidade de Estrasburgo, não menos notável que os seus antecessores. Só os que se dedicam ao estudo da Antiguidade, principalmente ao período de Augusto, é que podem fazer uma ideia do valor desse professor no campo da epigrafia e da arqueologia romana.

Atualmente, esta regendo a cátedra de História da Civilização Moderna e Contemporânea o professor Émile-Guillaume Léonard, da Faculdade de AixProvence, grande conhecedor da história social da França e da Itália na época moderna. 
Ora, todos esses professores pertencem ao célebre círculo da revista fundada em 1929, Annales d'Histoire Économique et Sociale, dirigida magistralmente por Lucien Febvre e pelo malogrado medievalista Marc Bloch, herói da Resistência francesa, fuzilado pelos nazistas de forma dramática em 1944. Assim, tivemos, desde 1934 até hoje, durante 14 anos, um ensino de História orientado mais para os estudos econômicos e sociais do que para outros setores, formando, pois, uma bela unidade, responsável sem dúvida pela homogeneidade que se nota entre os jovens professores de História formados pela nossa faculdade.

As outras cadeiras de História da faculdade orientam-se no mesmo sentido. A de História da Civilização Americana, regida pelo nosso amigo e colega dos bancos escolares desta faculdade e da Faculdade de Direito, o licenciado Astrogildo Rodrigues de Mello, tem procurado desenvolver o ensino recebido de seus mestres e, se tivesse de fazer sua aula inaugural sobre este assunto, fála-ia, estamos certos, bem semelhante à nossa.

A cátedra de História da Civilização Brasileira, regida primeiramente por Afonso d'Escragnolle Taunay e atualmente pelo professor Alfredo Éllis Júnior, tomou também o mesmo rumo que as outras suas companheiras.

Aqui pedimos nos seja permitido ressaltar mais uma vez - sem deixar de reconhecer o valor de nossos mestres nacionais - $\mathrm{o}$ alto papel desempenhado pelos professores franceses na formação de nossa cultura e na formação de verdadeiras escolas de suas especialidades. Assim, os licenciados em Geografia e História, Filosofia, Ciências Sociais, Letras e Matemática, muito lhes são devedores. E, se no futuro, eles forem passando suas cátedras aos discípulos que formaram, como é natural que aconteça, nunca deveremos deixar de fazê-los vir até nós como professores visitantes, trazendo-nos sempre os últimos ensinamentos e as experiências da ímpar cultura francesa. Sem isso, se permanecerem as atuais condições de ensino, não teremos uma verdadeira faculdade, onde ao lado da pesquisa deve existir a investigação e transmissão de conhecimentos científicos.

Ao vê-los aqui reunidos, colegas e alunos das diversas seções desta faculdade, não podemos deixar de falar sobre um dos problemas máximos da nossa universidade: a falta de um espírito universitário que se nota, em geral, nos alunos dos diversos institutos universitários e, em particular, nos alunos dos diversos departamentos de nossa faculdade. Isso se explica, em grande parte, 
pela falta de um edifício próprio, o que nos tem conduzido a um verdadeiro nomadismo através de prédios os mais diversos

Na verdade, fundada em 1934, a nossa faculdade teve os seus cursos iniciados na Faculdade de Medicina, de onde fomos desalojados em 1938. Depois, a parte de Letras instalou-se no local onde se erige hoje a Biblioteca Municipal. Em 1939, as seções de Letras localizaram-se na alameda Glette, de onde logo saíram para aí serem instaladas as seções de Química e História Natural, vindas da Faculdade de Medicina. As seções de Letras, continuando a sua peregrinação, instalaram-se aqui, na praça da República, no $3^{\circ}$ andar do extinto Instituto de Educação da Universidade de São Paulo. Com as seções de Matemática e Física deu-se o mesmo. Elas foram desalojadas da Escola Politécnica e acabaram em prédios alugados, absolutamente impróprios para o ensino e a pesquisa. Como vemos, a faculdade teve as suas seções completamente espalhadas, com os cursos de Matemática, Física, Química, Ciências Naturais afastados das seções chamadas de Letras e da administração. O malefício que isso acarretou para a própria vida da faculdade ninguém em sã consciência poderá deixar de reconhecer. Os alunos de diversas seções e até professores e assistentes se ignoram, formando verdadeiras ilhas culturais, quando tudo indica que a maior convivência traria mais vantagens para a formação de um verdadeiro e são esprit de corps. Como está anunciada a compra de dois prédios para a Faculdade, esperamos que talvez seja possível reunir alguns dos cursos até hoje dispersos. Pelo menos estaremos em casa própria e poderemos encarar o futuro com mais confiança, a espera dos edifícios definitivos da faculdade na Cidade Universitária.

Essa instabilidade e insuficiência de instalações tem se refletido no aproveitamento de nossos alunos. Sem falarmos da impossibilidade da ampliação de nossos laboratórios, nas próprias seções de Letras notamos que a capacidade didática de certos cursos já se acha esgotada. Os nossos professores e assistentes muitas vezes têm desejos de ampliar o número de suas aulas e veem seus esforços baldados pela falta absoluta de espaço. Os serviços administrativos, por outro lado, hipertrofiaram-se, cresceram desmesuradamente em comparação com o aumento de número de salas de aula, nestes últimos 14 anos de vida da nossa faculdade. Essa situação foi apenas melhorada em 1948 com as novas instalações dos cursos de Filosofia, Pedagogia e Letras na rua São Luís. Fazemos votos para que nas novas instalações a parte destinada ao ensino e à pesquisa - aliás a única que justifica a manutenção da faculdade - seja melhor aquinhoada. 
Ao lado da precariedade e insuficiência das instalações, as dotações orçamentárias têm sido ridiculamente pequenas. Não se compreende instituição universitária sem uma biblioteca bem dotada. Ora, a nossa biblioteca central absolutamente não vem preenchendo os fins para que foi criada. Por falta de funcionários e material ou não, o certo é que ela não se acha fichada, sendo, portanto, inútil. Aliás, a doação de livros feita pelo governo francês em 1938, dez anos depois não está ainda completamente catalogada. Os papirófagos ameaçam a preciosa Coleção Lamego. É preciso fazer-se, com urgência, alguma cousa por ela, sob pena de a perdemos definitivamente. É devido à completa separação de porções da faculdade que assistimos ao espetáculo bizarro de departamentos possuírem verdadeiras bibliotecas próprias - algumas muito bem organizadas e conservadas - quando devia ser a biblioteca central a detentora de boa porção de livros aí existentes, ficando nos gabinetes e departamentos apenas obras de consulta imediata e os manuais mais indicados. Mas com a atual dispersão da faculdade, paradoxalmente, são as bibliotecas departamentais que possibilitam aos nossos alunos a bibliografia indicada nos cursos.

As próprias bibliotecas departamentais, em 1948, nada ou pelo menos muito pouca cousa puderam adquirir, estando muitas delas desfalcadas das novidades aparecidas sobre a sua especialidade, e talvez nunca mais se encontrarão esses livros em nosso mercado. Toda essa instabilidade é que explica porque muitos professores - pelo menos os dos cursos de Letras, no sentido amplo da palavra - possuem em casa verdadeiras bibliotecas particulares e em dia com a matéria que lecionam. Essas bibliotecas, em face da situação, são transformadas em bibliotecas circulantes, ante a falta de livros na biblioteca central e nas bibliotecas departamentais. Esse é pelo menos o nosso caso. A penúria de livros e material didático em 1948 foi tal que muitas cadeiras de Letras se viram reduzidas a contar apenas com “giz e apagador de lousa”, e em 1949 a situação talvez permanecerá a mesma. Oxalá que a situação financeira do Estado melhore, para que a universidade possa ter verbas mais substanciosas.

Ao lado dessas deficiências bibliográficas notamos uma grande lacuna nas nossas bibliotecas: a falta de coleções de textos. Muito pouca cousa possuímos nesse sentido, mesmo na cadeira de História da Civilização Brasileira. E sem a cópia ou reprodução de documentos não podemos fazer os nossos alunos compreenderem bem o valor das fontes primárias da História. Pensamos que, através do serviço de filmes da Reitoria, talvez seja possível termos aqui re- 
produções exatas de textos, inscrições, documentos interessantes, portulanos, incunábulos etc.

Notamos também que se faz necessária uma nova cadeira ou pelo menos uma disciplina - a de História Ibérica - no grupo das cadeiras de História da faculdade. Servirá ela de introdução às cadeiras de História da Civilização Americana e Brasileira, porque a história da Península Ibérica é sempre posta em segundo plano na cadeira de História da Civilização Moderna e Contemporânea, em face do seu alentado programa. Esse curso já existiu em nossa faculdade e foi regido pelo prof. Astrogildo Rodrigues de Mello e inexplicavelmente desapareceu do currículo do curso de Geografia e História.

O nível dos candidatos que se apresentaram ao exame vestibular decresceu bastante, não obstante existirem honrosas exceções. A culpa desse fato evidentemente não é deles, mas sim do ensino de grau médio que receberam nos ginásios e colégios existentes no país. A prova de que esse ensino é falho a tivemos nos chamados "exames de suficiência" que, desde 1946, vêm sendo realizados na nossa faculdade. A média de reprovação desses professores com registro provisório é apavorante. E são eles que ministram o ensino por esse interior afora. Quanto aos professores do ensino oficial estamos assistindo a idêntico espetáculo. Aos nossos licenciados muitas vezes foram negadas cadeiras para regência interina no interior do Estado e aqui na capital, para serem entregues a pessoas completamente incapacitadas, mas possuidoras de boas recomendações políticas. Os resultados do concurso de ingresso ao magistério secundário e normal já publicados evidenciam de sobejo que, apesar da legislação deliberadamente organizada para beneficiar os professores leigos, sem formação universitária, os nossos licenciados têm levado a melhor, classificando-se nos primeiros lugares. E se tivéssemos tido mais apoio, teríamos tido muito mais licenciados a se submeterem ao concurso. Estudar na Faculdade de Filosofia, Ciências e Letras da Universidade de São Paulo tem sido um verdadeiro sacrifício. Não importa, apesar de todos os percalços, a nossa faculdade acabará vencendo, quer queiram quer não, pela massa e pela qualidade de seus licenciados regularmente formados nos princípios universitários. É mister apenas que se amiúdem os concursos, que os transformem no excelente sistema de agregation que tão úteis serviços tem prestado ao ensino secundário e superior em França.

Meus senhores. 
Se resolvido for, como esperamos, o problema da “casa própria” para a faculdade, muitos dos males aqui apontamos poderão ser atenuados, senão sanados definitivamente.

E, sendo a História, como realmente o é, o estudo cientificamente organizado das diversas atividades e das diversas criações dos homens d'antanho, como acentuamos atrás, o futuro historiador que tratar da história da faculdade, estudando cientificamente as diversas atividades e criações do Homem de "hoje", certamente concluirá que o ano de 1949 terá sido um ano crucial, que marcará em todos os setores uma ascensão mais rápida no sentido do progresso, da pujança e da vitalidade da nossa faculdade.

Oxalá, assim praza a Deus! 